\title{
AMIZADE, PERTENCIMENTO E RELAÇÕES DE PODER NO FUTEBOL DE BAIRRO
}

\author{
Luiz Carlos Rigo*
}

\section{RESUMO}

O presente artigo tem como referência empírica o caso da Sociedade Recreativa Arealense, um clube esportivo-recreativo de bairro tradicional da cidade de Pelotas, fundado em 1920. O objetivo é analisar as práticas futebolísticas infames, ou seja, não famosas. Prioriza-se, no texto, uma reflexão sobre como este futebol se constitui e é constituído por uma sociabilidade específica, por sentimentos de pertencimento e por relações de poder. Para desenvolver o estudo, foi utilizada uma metodologia que alia fontes orais, escritas e imagéticas.

PALAVRAS-CHAVE: futebol - bairro - amizade - pertencimento

\section{INTRODUÇÃO}

W ste artigo procura construir parte das memórias da Sociedade ReCreativa Arealense, um clube de futebol, social e recreativo, localizado em um bairro de classe popular da cidade de Pelotas, Rio Grande do Sul, fundado em 1920.

Mais do que datas históricas ou a participação de um ou outro indivíduo, a intenção foi fazer uma análise genealógica do clube, em especial do futebol, ressaltando os significados políticos e socioculturais que esse futebol de bairro - um Futebol Infame ${ }^{1}-$, possui para os seus adeptos, e para o bairro onde ele acontece.

Para desenvolver o estudo, além do suporte bibliográfico, utilizamos os registros escritos e imagéticos (fotografias) e dois depoi-

* Doutor em Educação pela Unicamp, professor adjunto da Escola Superior de Educação Física da Universidade Federal de Pelotas e líder do Grupo de Pesquisa Estudos Culturais em Educação Física. 
mentos orais, um feito com um dirigente do clube (Jorge Edi Bainy) e outro com um jogador que foi goleador do time em várias temporadas e atuou no clube por mais de uma década (Chaguinha). O uso dessas fontes orais deu-se segundo os princípios utilizados pela Metodologia da História Oral. ${ }^{2}$

\section{O CASO DA S. R. AREALENSE: SUA FUNDAÇÃO E MANUTENÇÃO}

Nascida, organizada, freqüentada e mantida predominantemente por moradores do Areal, um bairro operário da cidade de Pelotas, a S. R. Arealense pode ser classificada como uma associação futebolística e recreativa de bairro. Com a sede social localizada na Avenida Barão de Corrientes, $n^{\circ} 204$, sua fundação remete ao longínquo 26 de julho de 1920, data que faz do Arealense um dos clubes de futebol mais antigos do bairro. Um pouco dessa história Seu Jorge Edi assim abreviou para nós: "Aqui onde agora é a Supra-Arroz, antigamente era uma fábrica, e ali tinha também uma venda, e o pessoal dessa fábrica se reuniu e formou o Arealense em 1920" (BAINY, 1999). ${ }^{3}$

Sobre os primeiros times de futebol no bairro Areal, no início do século, Seu Jorge Edi observou que há indícios, comentários, de que existiram outros times no bairro já antes de 1920. Segundo ele, um desses times se chamava Sul-América, mas "seus participantes não formalizaram nada", e ele logo se dissolveu. Posteriormente, "praticamente aquela mesma turma, em 1920, fundou outro clube a que deu o nome de Arealense". ${ }^{4}$

Ainda sobre os passos iniciais do Arealense, os vínculos que possuía com outros clubes da cidade, a definição das cores e do escudo, Seu Chaguinha acrescentou: "Parece que é assim porque o primeiro fardamento do Arealense foi o Pelotas quem deu. Isso é o que eu ouvi falar; parece também que quando fundaram o Arealense, lá tinha gente que jogava no Pelotas. Você pode notar que o distintivo é quase igual" (RODRIGUEZ, 1999). ${ }^{5}$

Diferente dos clubes profissionais, o futebol de bairro nunca pôde contar com o dinheiro dos ingressos nem com grandes patrocínios. Por ocorrer também aos finais de semana, esse futebol acabou se constituindo num evento paralelo ao futebol dos clubes maiores da 
cidade. Só que, diferente daqueles, o futebol de bairro nunca atraiu um interesse maior da grande imprensa da cidade, dependendo, quase exclusivamente, dos esforços dos seus autores, sendo escassos e parcos os apoios econômicos que vinham de fora do grupo. O Arealense não fugiu à regra. Ele se estruturou e se manteve em atividade, principalmente, graças à disposição, à vontade e ao trabalho de seus jogadores, dirigentes e colaboradores mais próximos.

Além de se responsabilizar pela conservação do fardamento, os jogadores também pagavam a sua passagem quando tinham que se deslocar para jogar "fora de casa", "ou se ia num ônibus ou se ia num caminhão, mas cada um pagava... e quem não podia os outros ajudavam" (RODRIGUES, 1999). Às contribuições individuais, diretas, somavam-se as arrecadações indiretas que provinham do lucro da "copa" - bebidas que eram vendidas quando os jogos eram em seu campo das festas esportivas e dos eventos sociais.

A organização de eventos sociais tinha uma importância singular: além de auxiliar economicamente, eles serviam para aproximar e fortalecer os vínculos existentes entre os moradores do bairro, familiares e torcedores com o clube. "Mais era baile, diversão. Antes de nós fazermos a sede, nós alugávamos. Ali onde é o posto médico agora, era uma Sociedade (Sociedade Beneficente Caixa do Socorro). Depois começamos a fazer bailes na própria sede. Fizemos uma sede grande, inaugurou em 1961" (BAINY,1999).

Assim como fizera Seu Jorge Edi Bainy, Seu Chaguinha destacou a organização e a união do grupo - sempre balizada pelo futebol — em torno do clube. Pacto coletivo que foi decisivo para o clube construir sua sede social e comprar o campo de futebol, que no início era emprestado. Quanto ao campo e sede próprios, Betty Schifnagel assinala que, principalmente para a sede, há uma valorização diferenciada por parte dos clubes de várzea. Para alguns, ela não parece ser tão importante, podendo "funcionar na casa de um jogador." Ou "será alugada — um porão ou uma garagem é o suficiente". Já para outros clubes, destaca a autora, a posição é bastante diferente. Eles "fazem questão absoluta de sede e campo próprios (sem o quê, o time se sente moralmente diminuído)" (SCHIFNAGEL, 1979, p. 117).

A ênfase e o valor que os dois entrevistados atribuíram ao movimento que proporcionou condições para a aquisição da sua sede própria 
explicitam a importância que para o Arealense teve essa conquista. Os diferentes significados e a importância (ou a falta dela) atribuída pelos clubes à sede está relacionada com o seu perfil. Quanto maior é a sua intervenção cultural - realiza bailes e outras atividades sociais, ou seja, não se restringe ao futebol -, mais importância ele tende a atribuir à sede.

\section{CAMPEONATOS, EXCURSÕES E AMISTOSOS: A VIDA FUTEBOLÍSTICA DE UM CLUBE INFAME}

As atividades esportivas realizadas pelo Arealense seguiam um estilo bastante parecido com o da maioria dos outros pequenos clubes. De acordo com os nossos entrevistados, até meados de 1950 ele disputava, predominantemente, jogos amistosos. Partidas que eram combinadas no sistema de ida e volta, onde um time recebe o outro em seu campo e depois retribui a visita.

Além do primeiro e do segundo quadro, às vezes as disputas envolviam também times de veteranos e infantis, quando os clubes possuíssem essas categorias. "Uns tempos depois se 'formou-se a categoria dos veteranos'. Aí ficou infantil, veteranos, primeiro e segundo quadro. Houve uma época que jogavam as quatro equipes no mesmo dia. Veteranos e infantis de manhã, primeiro e segundo quadro à tarde." (BAINY, 1999).

O primeiro Campeonato Varzeano que contou com um grande número de times da cidade, segundo Seu Edi, ocorreu em 1952 e foi organizado pela Rádio Cultura. Esse Campeonato, como também os outros que posteriormente vieram a ocorrer, possuía uma primeira fase zonal, por bairros, e uma fase final que reunia campeões zonais.

O campeonato promovido pela Rádio Cultura não teve segunda edição. Somente posteriormente, em 1959, quando a Liga Pelotense de Futebol organizou seu departamento de futebol amador, o campeonato citadino varzeano foi reeditado, mantendo a mesma fórmula, uma primeira fase zonal e a final com os campeões de cada região. Com edições anuais, para o primeiro e segundo quadro, o campeonato varzeano voltou para ficar. Passou a fazer parte da agenda anual de muitos "pequenos" clubes, e seus episódios ajudaram a formar a memória afetiva de várias gerações de boleiros da cidade. "Bom, quando eu fui diretor, 
disputaram 40 clubes, em 1964 e 65 também, e cada clube podia inscrever quarenta jogadores. Eu organizei 1600 inscrições, todas as fichas rigorosamente em ordem alfabética" (BAINY, 1999).

De 1960 a 1993, a S. R. Arealense disputou a maioria das realizações desse certame, sempre com o primeiro e o segundo quadro, e conquistou vários títulos. O primeiro quadro foi campeão do bairro, primeira fase, em 1960, 62, 66 e 72, e o segundo foi em 1960, 67, 70. Mas 1989 foi o ano em que ocorreram as conquistas mais lembradas e festejadas pelo clube, quando o primeiro e o segundo quadro foram campeões citadinos. "Em 89 foi o único título que conquistamos da cidade... fomos campeões, segundo e primeiro quadro, do Areal, do torneio início da zona, do torneio início da cidade e do campeonato da cidade. Segundo e primeiro, arrematamos todos" (BAINY, 1999). Apesar do campeonato sempre envolver os dois quadros, havia uma valorização maior para a disputa que ocorria entre os primeiros quadros. Formados pelos "melhores" jogadores, era para eles que o olhar do clube e da torcida estava mais voltado. "Segundo quadro a gente não dava muita bola" (BAINY, 1999).

O primeiro quadro era o time principal. Desempenho físico e técnico, aliados à freqüência aos jogos, eram os critérios que definiam a equipe. Já o segundo quadro, além de ser um "laboratório" para o primeiro. (nele se testava e se lapidava os jogadores mais jovens que despontavam no clube), era também o espaço para quem estava um pouco fora de forma ou para quem gostava de jogar, mas não era muito habilidoso (membros da diretoria do clube). O segundo quadro era uma mistura de "gurizada mais nova, velhos que já estavam voltando e aqueles que nunca iam chegar no primeiro" (RODRIGUES, 1999).

Apesar da importância do campeonato citadino (que começava no primeiro semestre, abril ou maio, e se estendia pelo segundo, com a final geralmente próxima ao fim do ano), os clubes não restringiam a sua vida esportiva a ele. Os tradicionais jogos amistosos, com as trocas recíprocas de visitas, e os torneios relâmpagos, que aglutinavam vários times num único dia no mesmo campo, continuaram presentes na vida dos clubes.

Assim que conseguiam certa estabilidade, alguns clubes ousavam um pouco mais. Além dos corriqueiros jogos amistosos frente aos times da vizinhança, de tempos em tempos eles planejavam alguma excursão para um lugar mais distante. Nessas viagens futebolísticas, além 
dos jogadores iam as mulheres, os filhos, as namoradas, os amigos e os torcedores.

Das diversas excursões que o Arealense realizou, Seu Jorge Edi deu grande ênfase a duas, ambas para São Leopoldo, RS - cidade próxima à Capital, distante mais ou menos $300 \mathrm{~km}$ de Pelotas. A primeira delas ocorreu em 1966 e a segunda em 1970. Essas duas excursões, que não se restringiram ao jogo de futebol, foram recordadas por Seu Jorge Edi com entusiasmo e com saudade. Lembro, disse ele, que "nós saíamos daqui às duas da madrugada. De manhã cedo nós estávamos em Porto Alegre. O pessoal tomava café por ali, dava uma passeada. Uma vez conhecemos o Olímpico [Estádio do Grêmio], outra vez conhecíamos outra coisa. Íamos pro Jardim Zoológico. De tarde jogávamos futebol e depois vínhamos embora. Chegávamos de volta de noite, o dia inteiro na rua" (BAINY, 1999).

Apesar dos jogos do Arealense envolverem times das diferentes regiões da cidade, era no próprio bairro Areal que estavam os seus rivais mais tradicionais. As fases zonais do campeonato citadino potencializavam ainda mais a rivalidade que costumava existir entre times de um mesmo bairro. No Areal, além do Arealense, ao longo dos anos surgiram vários outros times de tradição. Entre eles podemos destacar: Planalto, Sul-América, São Pedro, Oriental, 15 de Outubro, São Paulo, Cabana, Atenas, Estrela Solitária, Estrela do Sul. Quando dois desses times se enfrentavam, os ânimos exaltavam-se. Um dos principais clássicos do bairro foi, por muito tempo, Arealense x Sul-América. Sempre que se enfrentavam em jogo amistoso ou pelo campeonato, a movimentação, os comentários e as provocações comuns de toda rivalidade futebolística tomavam conta do bairro. O jogo poderia ser no Estádio das Areias, campo do Arealense, ou no Estádio da Montanha, campo do Sul-América, mas a presença da torcida dos dois clubes era certa. Atrás da goleira adversária ou colados nas laterais do campo, com as bandeiras em punho, os torcedores não mediam esforços para provocar, perturbar e tentar intimidar árbitros e jogadores adversários. Como bem destacou Seu Chaguinha: "Arealense e Sul-América pro bairro era considerado um Bra-Pel"6 (RODRIGUES, 1999).

Em certos momentos a rivalidade era tamanha que se estendia para fora do campo; servia como um marco que ajudava a delimitar a territorialidade dentro do bairro. "O Areal era meio dividido, era mais 
Sul-América na rua das Traíra e, mais pro fundo, era mais Arealense" (RODRIGUES, 1999). Mesmo nos dias de semana, que teoricamente nada tinham a ver com futebol, os jogadores, torcedores e dirigentes de ambos os clubes tinham seus locais de encontro preferidos um tanto diferenciados. "Na padaria em que eu trabalhava e de que era dono, à noite se reunia a turma do Arealense, ia toda pra li. E no bar Farroupilha, que era um bar uns 150 metros longe da padaria, era a turma do Sul-América que se encontrava" (RODRIGUES, 1999).

As relações de poder não se restringiam às disputas entre times rivais; elas se constituíam também no interior de cada clube. A posição de titular, principalmente do primeiro quadro, era sempre bastante disputada e não faltar aos jogos era uma das condições para não perdê-la. "No caso do Arealense tinha um cara que se chamava Ares Nunes, não se chamava de treinador naquela época, acho que se chamava de Capitão Geral. Ele era muito enérgico. Botava o cara, e aí se tu falhava, no outro domingo ele botava outro, que podia até ser inferior, mas que só seria tirado depois de um certo tempo" (RODRIGUES, 1999).

Seguidamente apareciam disputas também entre os jogadores oriundos do próprio bairro, os chamados "prata da casa" — com um ou outro que vinha de fora. Esse "estrangeiro" podia ser alguém que fora convidado para começar a fazer parte do time ou apenas para reforçar a equipe em uma determinada competição. A segunda opção, que era reforçar a equipe com alguém de fora, normalmente causava transtornos ao grupo. "Na minha época a maioria era do bairro. Muitas vezes eles experimentavam levar gente de fora, mas gente de fora era aquele problema: tirava o da casa pra botar o de fora que, às vezes, era pior que o da casa, mas como era de fora tinha que botar" (RODRIGUES, 1999).

A disputa pela titularidade, agregada à rivalidade, fortalecia os laços de pertencimento existentes entre jogadores, clube e torcedores. Mudar de time, jogar um ano em um e o outro ano em outro, não era proibido, mas, além de pouco comum, nem sempre era bem aceito. Quando a troca era entre dois times rivais, o risco era ainda maior. Seu Chaguinha contou o episódio de uma competição da qual o Arealense não iria participar, e dois dos seus jogadores, um zagueiro e um centro médio, decidiram assinar pelo Sul-América. Assim que a notícia se espalhou pelo bairro, houve um comentário geral, "foi um baaah, esses caras não podiam jogar pro Sul-América” (RODRIGUES, 1999). 
Posteriormente, passado o impacto inicial, aparentemente o fato tinha sido assimilado pelos dois clubes. Tudo parecia estar transcorrendo razoavelmente até que em um jogo, em que ventava muito, bateram um escanteio e o centro-médio foi tirar de cabeça e fez um gol contra. "Pronto". Foi um acidente, mas era o que faltava, "a torcida gritava: é vendido, esse é vendido, não é nosso, isso vem do Arealense, não é nosso" (RODRIGUES,1999).

\section{O BAIRRO E O CLUBE DE FUTEBOL}

Pierre Mayol (1996), ao falar sobre os bairros, comenta como eles interferem, condicionam e ajudam a produzir um estilo de vida em seus moradores com seus códigos de conduta. Para o autor, trata-se de "uma arte de conviver com parceiros (vizinhos, comerciantes) que estão ligados a você pelo fato concreto, mas essencial, da proximidade e da repetição" (MAYOL, 1996, p. 39). O exemplo da S. R. Arealense mostra como os clubes esportivos sociais através do futebol ocupam um lugar de destaque dentro dos bairros.

Além de atuarem agenciando pertencimento, identificam seus membros entre si e com o bairro, os clubes de futebol agem como catalisadores que concentram e reproduzem os afetos, os códigos e os conflitos que flutuam pelas ruas. Por sua capacidade de agregar e interagir com os moradores, eles se tornam agenciadores de sociabilidade, um lugar onde se forjam sentimentos e valores, um espaço utilizado para administrar as rivalidades, as diferenças e as tensões intrínsecas a todo bairro: "Cada clube desses tinha um grupo ligado a eles" (RODRIGUES, 1999).

Poder-se-ia dizer que os clubes são pequenos fragmentos do bairro, já que se condicionam mutuamente. O futebol, as festas e os bailes fazem dos clubes um espaço compartilhado pelo bairro, principalmente nos finais de semanas, quando eles se tornam pontos de encontro. Ao redor do campo de futebol, escorado na copa ou nos bailes e festas, transitam tanto os freqüentadores assíduos como novatos, curiosos do próprio bairro, ou visitantes da redondeza. $\mathrm{O}$ clube se transforma em um lugar propício para encontros, um espaço que contribui para aproximar amigos, conhecidos e vizinhos quase anônimos. Proximidade fundamental para forjar um estado para melhor "conviver" entre toda a vizinhança. 
Simoni Guedes (1998), ao analisar o futebol de bairro, acentua que ele ajuda a forjar redes de sociabilidade onde, segundo ela, joga-se e negocia-se, para além do futebol, valores, idéias, informações sobre o mercado de trabalho e sobre locais de moradia. A autora observa que "os laços são mais fortes no local de residência, estendendo-se e esgarçando-se pelas áreas próximas” (GUEDES, 1998, p. 85).

Ambos, bairro e clube, longe de serem espaços harmônicos, idealizados, são constituídos, também, por "relações de poder". ${ }^{7}$ As permanentes divergências e disputas que neles germinam são balizadas e administradas por determinados pactos sociais que criam obrigações e estabelecem vínculos comuns a todos que neles se inserem. Ambos, clubes e bairros, mais do que por leis padronizadas, tendem a se orientar por certas posturas éticas contingentes e singulares. "A prática do bairro é uma convenção coletiva tácita, não escrita, mas legível por todos os usuários através dos códigos da linguagem e do comportamento" (MAYOL, 1996, p. 47). Mais do que uma normatização, esse pacto ético visa forjar um sentimento favorável a uma coletividade. Coletividade entendida aqui como "um lugar social que induz um comportamento prático mediante o qual todo usuário se ajusta ao processo geral do reconhecimento, concedendo uma parte de si mesmo à jurisdição do outro" (MAYOL,1996, p. 47).

A análise feita da experiência da S. R. Arealense propiciou identificar algumas singularidades do futebol de bairro, como a sua peculiar maneira de lidar com a transferência dos jogadores de um clube para outro. Quando a troca se dá entre times rivais, vimos que há resistências a ela. Porém, quando se trata de deixar o time para ingressar no futebol profissional a aceitação é quase unânime - a saída é comemorada, é contada em alta prosa e passa a fazer parte da memória do clube. Orgulhosamente Seu Jorge Edi recordou alguns jogadores que foram revelados pelo Arealense e viraram profissionais.

Semelhante aos pais que vêem seus filhos irem para o mundo, o bairro cultua com orgulho os jogadores que saíram de seus times e fizeram sucesso no competitivo mundo do futebol profissional. Através da memória e da oralidade, os antigos companheiros de clube e os moradores do bairro se encarregam de passar para as novas gerações os nomes, as qualidades futebolísticas, as manhas e um pouco da trajetória desses jogadores que ganharam certa fama. A alegria e o orgulho com 
que a maioria dos moradores narra e guarda na memória as histórias desses jogadores mostram alguns laços de pertencimento instituído entre futebol e bairro.

Ao mesclar sentimentos clubísticos forjadores de rivalidades com laços de pertencimento ao bairro, o futebol cria elos de interação e interconexões com todo o resto da cidade. Essa probabilidade aumenta principalmente se concordamos com Pierre Mayol (1996, p. 40), quando ele pressupõe que "o bairro é, quase por definição, um domínio do ambiente social, pois ele constitui para o usuário uma parcela conhecida do espaço urbano na qual, positiva ou negativamente, ele se sente reconhecido". "O bairro", prossegue o mesmo autor, "se inscreve na história do sujeito como a marca de uma pertença indelével na medida em que é a configuração primeira, o arquétipo de todo processo de apropriação do espaço como lugar da vida cotidiana pública" (MAYOL, 1996, p. 44).

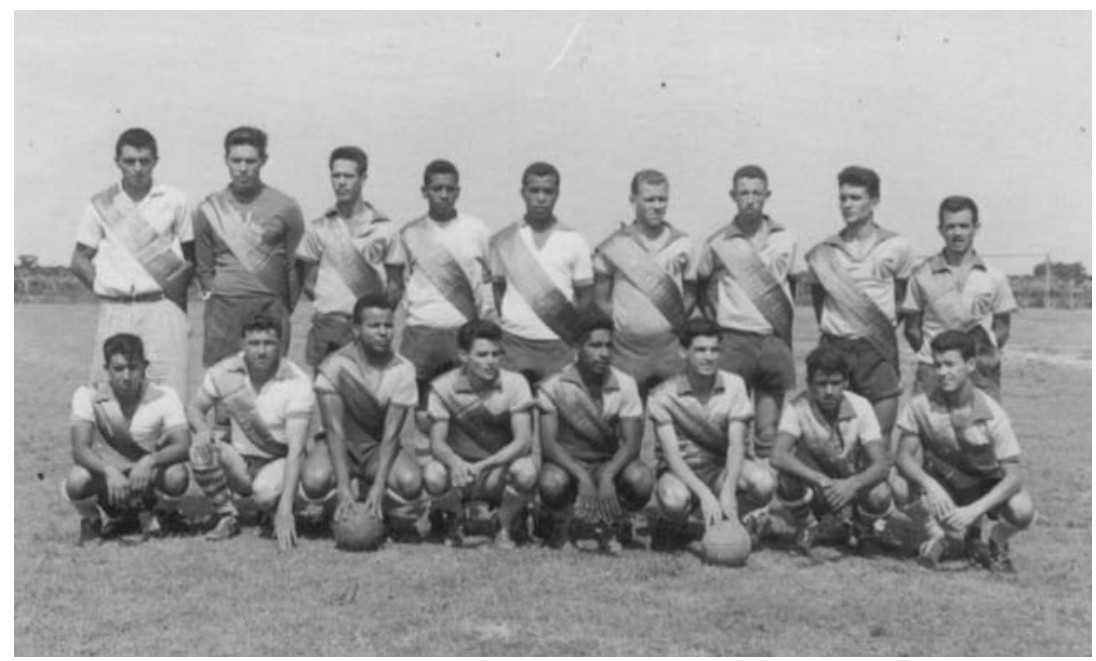

$1^{\circ}$ Quadro - S. R. Arealense, equipe campeã do bairro Areal em 1962

Fonte: Acervo particular de Jorge E. Bainy. Em pé (da esquerda p/ direita): treinador, Jorge E. Bainy, Valentim Oliveira, João Lourenço (Pechada), Charuto, Dindin, Olicio Rosa, José C. Rodrigues (Cabide), Cláudio Cunha, Aglair Conceição (Leco). Agachados (mesma ordem): Adão Costa, Clóves Penadez, Valdir Cardoso, Dilson Ramalho, Edemar Soares (Marzinho), Wilson Rodrigues (Chaguinha), Nílvio Santos, Paulo Argou (Pipico). 


\section{CONSIDERAÇÕES FINAIS}

As memórias da Sociedade Recreativa Arealense mostram a multiplicidade de elementos presente na construção de um "estilo" singular de futebol, que no texto foi tratado por como "Futebol de Bairro", que se mantêm vivo e atuante tanto na cidade de Pelotas como na maioria das demais cidades de nosso país. Ao classificar a S. R. Arealense como um Clube de Bairro não se ignorou a presença de outros traços identitários na sua constituição, como classe social, descendências étnicas e também outras afinidades relacionadas com as contingências históricas e geográficas do bairro e do clube. Nesse sentido, o adjetivo Futebol de Bairro foi utilizado não para expressar uma identidade única e excludente, mas sim para ressaltar uma das marcas constitutivas que acompanhou as memórias da Associação Arealense e que se faz presente ainda hoje. ${ }^{8}$

O Futebol de Bairro, assim como outras práticas culturais que aí são produzidas ou apropriadas, atua como um fomentador da inquietude, potencializando o que Michel de Certeau (1994) denominou de "inventividade" do cotidiano que, segundo ele, é uma "arte de fazer" que acompanha os produtores culturais das classes populares.

Como denunciou Richard Sennett (1988), vivemos em uma época onde se exacerba o eu em detrimento do convívio social e predomina o ceticismo e a descrença nas esferas públicas como lugar de lazer, de convivência e de sociabilidade. Nesse contexto de crises das práticas de socialização, o Futebol de Bairro atua como uma intervenção política que se contrapõe aos discursos das "tiranias da intimidade".

Francisco Ortega $(2000,2002)$ é outro autor que denuncia a crescente desqualificação das práticas de sociabilidade e dos espaços públicos. Ortega alerta sobre a importância de se restituir o sentido público e político da amizade. Para Ortega (2000, p. 56), "a amizade constitui uma alternativa às velhas e rígidas formas de relação institucionalizadas, representando igualmente uma saída ao dilema entre uma saturação de relações, surgidas da dinâmica da modernidade, e uma solidão ameaçadora".

Ao referendar antigas e (re)inventar novas formas de sociabilidade, entendemos que o Futebol de Bairro, assim como outras práticas de lazer similares, desempenha um papel social e cultural estratégico para pensarmos novas "políticas da amizade" (ORTEGA, 2000). 
Audacioso, insistente, político e astuto, esse Futebol Infame, que aqui denominamos de Futebol de Bairro, sobrevive e prolifera-se, e para isso ele conta também com um determinado grau de disciplina e persistência dos seus autores. Para alguns, como Seu Jorge Edi, tamanho é o envolvimento, que essa perseverança beira a obstinação, sensação que ele passa quando manuseia os seus cadernos de anotações ou durante certas passagens de seu depoimento, como por exemplo, no momento em que ele lastima o cancelamento do setor de futebol da S. R. Arealense a partir de 1993. "Foi a primeira vez que parou, e tu sabes que se eu tivesse uns dez, quinze ou vinte anos a menos eu não tinha deixado parar. Ah, não tinha" (BAINY, 1999).

\section{Friendship, bonding, and power relations in neighborhood football}

\section{ABSTRACT}

This articles has, as its empirical reference, the case study of Sociedade Recreativa Arealense, a sports $\&$ health club in a traditional neighborhood in the city of Pelotas, founded in 1920. The main aim is to analise non-famous football practices. The text prioritizes a reflection on how these football practices constitute, and are constituted by a specific type of socialization, by feelings of bonding and power relations. The chosen methodology used to develop this research study integrates spoken, written, and pictorial sources.

KEYWORDS: football - neighborhood - friendship - bonding

Amistad, pertenecimiento y relaciones de poder en el fútbol de barrio

\section{RESUMEN}

El presente artículo tiene como referencia empírica el caso de la Sociedad Recreativa Arealense, un club de barrio deportivo recreativo tradicional de la ciudad de Pelotas, creado en mil novecientos y veinte (1920). El objetivo está en analizar las prácticas futbolísticas infames, es decir, no famosas. Se prioriza, en el texto, una reflexión sobre cómo este fútbol se constituye y es constituido por una sociedad específica, por sentimientos de pertenencia y por relaciones de poder. Para desarrollar el estudio, se utilizó una metodología que coliga fuentes orales, fuentes escritas y fuentes de imágenes.

PALABRAS-CLAVE: fútbol - barrio - amistad - pertencimento

\section{NOTAS}

1 O termo Infame está sendo usado inspirado no sentido que lhe atribui Michel Foucault em seu texto "A vida dos homens infames". 
Ao garimpar fragmentos dos discursos emitidos pelas "letters de cachet", Foucault assinala que irá se ater àqueles endereçados a sujeitos "infames". "Infâmia estrita" demarca o autor. E acrescenta: "aquela que, não sendo temperada, nem de escândalo ambíguo, nem de uma surda admiração, não é compatível com nenhuma espécie de glória". Ou seja, o termo é usado não no sentido valorativo, moral, mas sim como um adjetivo para identificar sujeitos não famosos, sem fama (FOUCAULT, 1992, p. 103).

2 Apesar da Metodologia da História Oral não se constituir em um método único e universal, ela possui alguns princípios norteadores que orientam o uso acadêmico de fontes orais. Maiores considerações sobre a história oral consultar: "História oral: desafios para o século XXI", Marieta de Moraes Ferreira, Tania Fernandes, Verena Alberti (Orgs.), 2000. "Usos \& abusos da história oral”, Janaina Amado e Marieta de Moraes Ferreira (Orgs.), 1998. "Os desafios contemporâneos da história oral", Olga R. von Simson, 1997. "A voz do passado: história oral", Paul Thompson, 1992.

3 Depoimento concedido por Seu Jorge Edi Bainy na sua casa no Bairro Areal, Pelotas - RS, em 1999. Seu Jorge Edi nasceu em 1935 e já em 1950 entrou para a diretoria do Arealense onde atuou em diversas funções (tesoureiro, secretário, treinador e jogador do Segundo Quadro), sendo inclusive presidente em três gestões.

4 Este detalhe histórico ganha importância porque no bairro Areal existiram dois times chamados Sul-América. O mais antigo, a que seu Edi se referiu, é anterior a 1920 - no jornal da cidade Diário Popular encontrei várias referências a ele no ano de 1912. O outro Sul-América está em atividade até hoje; possui sua sede social localizada no Dunas, região pertencente ao bairro Areal. Esse segundo irá aparecer nos depoimentos orais e nos registros escritos como o principal rival do Arealense após os anos 50. De acordo com seus estatutos, ele foi fundado em 29 de outubro de 1928 e reorganizado em $1^{\circ}$ de janeiro de 1939 (ESTATUTO, 1930, capítulo I, p. 1).

5 Depoimento concedido por Seu Chaguinha em sua padaria em Pelotas - RS, em 1999. Seu Chaguinha nasceu em 1936 e se chama Wilson da Silva Rodrigues. Além de dirigente, ele foi um dos principais artilheiros do Arealense. Começou a jogar pelo clube quando ainda era adolescente (1953). Nos cadernos de anotações confeccionados 
por seu Jorge Edi Bainy, ele aparece como o artilheiro do time do primeiro quadro nas temporadas de 1960, 1961, 1962 e 1963, com $16,7,16$ e 17 gols, respectivamente.

6 Denomina-se de Bra-Pel o clássico que envolve os dois maiores times de futebol da cidade: G. S. Brasil e E. C. Pelotas.

7 O conceito de Poder está sendo utilizado no sentido que lhe atribui Michel Foucault, como uma marca constituinte das práticas sociais, que produz e é produzido pelos sujeitos que estão nela inseridos; tanto na prática discursiva ou não discursiva. Para Foucault o poder não é apenas negativo, punitivo e/ou proibitivo. Aliás, o autor destaca que o grande mérito e eficiência do poder está justamente na sua maleabilidade, sua sutileza e na sua capacidade de ser produtivo, sedutor, prescritivo ou mesmo protetor, características que o autor identifica, por exemplo, junto às práticas que ele denomina de "Poder Pastoral" e de "Bio-Poder". Maiores considerações sobre as análises genealógicas do poder em Michel Foucault consultar: Dreyfus e Rabinow, Michel Foucault: uma trajetória filosófica (para além do estruturalismo e da hermenêutica), 1995.

8 O tema dos vínculos identitários estabelecidos pelos clubes de futebol é um tema ainda pouco estudado no futebol brasileiro. Leonardo Pereira (2000) mostra que já no futebol do Rio de Janeiro dos anos 20 e 30 os clubes estabeleciam vínculos identitários de formas bastante diferentes. Já naquela época muitos clubes estabeleciam mais de um vínculo identitário como bairro e etnia, bairro e fábrica, bairro e classe social e também flexibilizavam esses vínculos de acordo com as necessidades e as contingências de diferentes momentos históricos.

\section{REFERÊNCIAS}

AMADO, J.; FERREIRA, M. de M. (Coord.). Usos \& abusos da história oral. Rio de Janeiro: Editora da Fundação Getúlio Vargas, 1998.

CERTEAU, M. A invenção do cotidiano: 1. artes de fazer. Petrópolis, RJ: Vozes, 1994. 
DREYFUS, H.; RABINOW, P. Michel Foucault: uma trajetória filosófica (para além do estruturalismo e da hermenêutica). Rio de Janeiro: Forense Universitária, 1995.

ESTATUTO do Esporte Clube Sul-América. Pelotas: [s.e.], 1930. (Mimeo). FOUCAULT, M. A vida dos homens Infames. In: . O que é um autor? Lisboa: Veja, 1992.

FERREIRA, M. de M.; FERNANDES, T.; ALBERTI, V. (Orgs.). História oral: desafios para o século XXI. Rio de Janeiro: Fiocruz/ Casa de Oswaldo Cruz / CPDOC Fundação Getúlio Vargas, 2000.

GUEDES, S. L. O Brasil no campo de futebol: estudo antropológico sobre os significados do futebol brasileiro. Niterói, RJ: EDEFF, 1998.

MAYOL, P. Morar. In: CERTEAU, M.; GIARD, L.; Mayol, P. A invenção do cotidiano: 2. Morar, cozinhar. Petrópolis: Vozes, 1996.

ORTEGA, F. Para uma política da Amizade: Arend, Derrida, Foucault. Rio de Janeiro: Relume Dumará, 2000.

. Genealogias da Amizade. São Paulo: Iluminuras, 2002.

PEREIRA, L. A. de M. Footballmania: uma história social do futebol no Rio de Janeiro - 1902-1938. Rio de Janeiro: Nova Fronteira, 2000.

SCHIFNAGEL, B. Caracterização geral do futebol de várzea como atividade popular de lazer. CERU (Centro de Estudos Rurais e Urbanos), São Paulo, Caderno n. 12, 1ª série, p. 110-125, set. 1979.

SENNETT, R. O declínio do homem público: as tiranias da intimidade. São Paulo: Companhia das Letras, 1988.

SIMSON, O. R. de M. von (Org.). Os desafios contemporâneos da história oral. Campinas: Área de Publicação CMU/Unicamp, 1997.

THOMPSON, P. A voz do passado: história oral. Rio de Janeiro: Paz e Terra, 1992.

\section{Entrevistas:}

Jorge Edi Bainy, Pelotas, 1999.

Wilson da Silva Rodrigues, Pelotas, 1999. 


\section{Cadernos de anotações:}

BAINY, J. E. Livro de anotações de jogos de 1960 a 1964. Pelotas. (Mimeo). . Livro de anotações de jogos de 1975 a 1984. Pelotas. (Mimeo).

Recebido: 28 de setembro de 2006 Aprovado: 6 de novembro de 2006

Endereço eletrônico: 1crigo@terra.com.br

Telefone: (53) 3272.2463 